Olgu sunumu / Case report

\title{
Unutulmuş parmak turnikesi
}

\section{Forgotten digital tourniquet}

\section{Ferhat Say}

\section{S. B. Samsun Eğitim ve Araştırma Hastanesi, Ortopedi ve Travmatoloji Kliniği, Samsun, Türkiye}

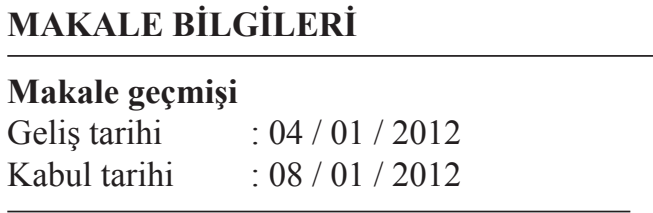

\section{Yazışma Adresi:}

Ferhat Say

Samsun Eğitim ve Araştırma Hastanesi, Ortopedi ve Travmatoloji Kliniği,

İlkadım, Samsun

e-posta: ferhatsay@gmail.com

\author{
Anahtar Kelimeler: \\ Parmak turnikesi \\ Basınc \\ Uygulama süresi \\ Komplikasyon
}

\section{Keywords:}

Finger tourniquet

Pressure

Application time

Complication

\section{ÖZET}

El ve ayak parmak cerrahisinde hemostaz sağlamak amacı ile parmak turnikeleri yaygın olarak kullanılmaktadır. Parmak turnikeleri uygulaması kolay, ucuz ve efektif yöntemlerdir. Komplikasyonlar uygulanan basınç ve süreyle ilişkilidir. Yazıda ayak başparmak cerrahisi sonrası parmak turnikesi 48 saat boyunca unutulan olgu sunulmuştur. Olgu medikal tedavi ve cerrahi debridman ve greftleme ile başarılı bir șekilde tedavi edilmiştir.

J. Exp. Clin. Med., 2012; 29:324-326

\begin{abstract}
Digital tourniquets are commonly used in foot and hand finger surgery for haemostasis. Digital tournuquets are easily applied, cheap and effective methods. Complications are related with applied pressure and duration. In this paper a case with a forgotten digital tourniquet on the finger for 48 hours following the hallux surgery was presented. The case was succesfully treated with medical therapy and surgical debridement and grafting. J. Exp. Clin. Med., 2012; 29:324-326
\end{abstract}

\section{Giriș}

El ve ayak parmak cerrahisinde hemostazı sağlamak amacı ile pek çok çeşit dijital turnike kullanılmaktadır. Uygulanacak cerrahi tek bir parmağa yönelik ise parmağın proksimaline uygulanacak turnike ile hemostaz sağlanır (Shaw ve ark., 1985). Dijital turnikelerin kullanımı güvenli ve efektif olmasına rağmen komplikasyonları ciddi sonuçlara yol açabilir. Komplikasyonların çoğu iskemiye veya uygulanan basıncın fazla olmasına bağlıdır (Ochoa ve ark., 1972; Dove ve Clifford, 1982).

Pek çok çeşit dijital turnike vardır. Turnikelerin uyguladığı basınç yönteme göre değişmektedir. Uygulama süresi tartışmalı olmakla birlikte 30 dakikanın altındaki sürelerde dijital turnikeler güvenli kabul edilirler (Smith ve ark., 2002). Yazıda dijital turnikenin 48 saat unutulması sonrasında dijital sinir kompresyonu ve iskemi gelişen bir olgu sunuldu.

\section{Olgu}

On altı yaşında bayan hasta sol ayak 1. parmağında ağrı ve şişlik sebebi ile kliniğimize başvurdu. Anamnezde 48 saat önce tırnak batması sebebi ile dış merkezde opere olduğu ve operasyondan önce cerrahi eldivenden kesilen halka şeklinde dijital turnike uygulandığı öğrenildi. Fizik muayenede sol ayak 1. parmak proksimalinde turnikenin bulunduğu görüldü. Turnike kesildikten sonra yapılan muayenede turnikenin uygulandığı bölgede cildin masere olduğu, yaygın ödem, şişlik 
ve konjesyonun olduğu görüldü. Tırnak yatağı medialinde geçirilmiş operasyona bağl $3 \mathrm{~cm}$ insizyon mevcuttu (Şek. 1). Şişlik ve ödem nedeni ile parmak hareketleri kısıtlı idi. Yapılan nörolojik muayenede parmağın tamamında anestezi olduğu görüldü.
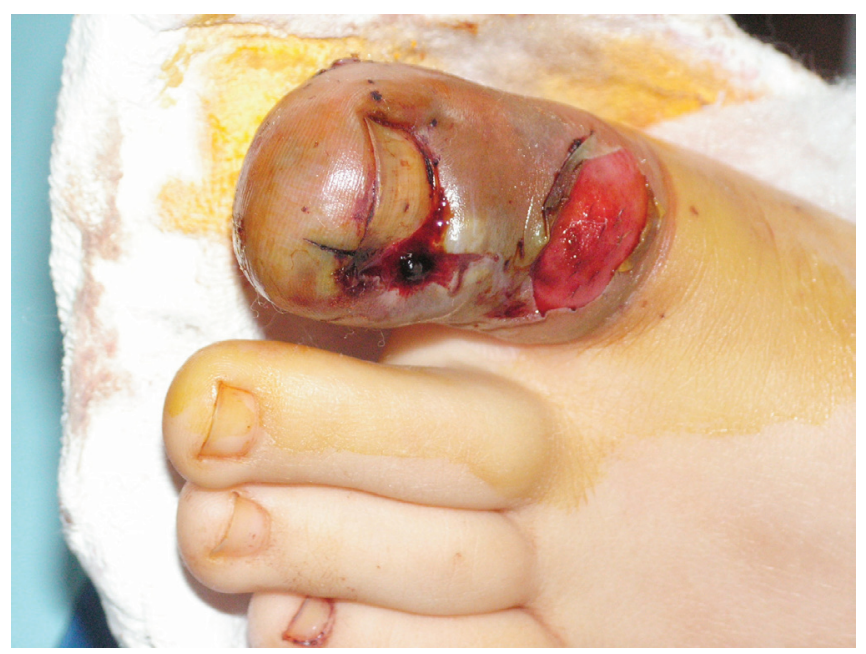

Şek. 1. Tedavi öncesi sol ayak 1. parmağın görüntüsü

Hastaya kısa bacak atel uygulanıp hospitalize edildi. Elevasyon uygulanıp 5 gün boyunca i.v. $1500 \mathrm{cc}$ dekstran ve pentoksifilin uygulandı. Asetilsalisilik asit $300 \mathrm{mg}$ günlük olarak verildi. Antibiyotik profilaksisi i.v. olarak verildi. Hastanın takibinde 5. günde siyanozu ve ödemi geriledi. Volar yüzde parestezi olduğu görüldü. 20. günde 1. parmak dorsalinden mediale uzanan yüzeyel nekrozu olan hasta Plastik ve Rekonstruktif Cerrahi kliniği tarafindan opere edildi. Operasyon sirasında 1. parmak distal falanks laterali ve proksimal falanks dorsalindeki tam kat olan defekt alanlar dışında nekroz altında sağlam epitel varlığı görüldü. Defekt alan inguinal bölgeden alınan splitt thickness deri grefti ile onarıldı (Şek. 2).

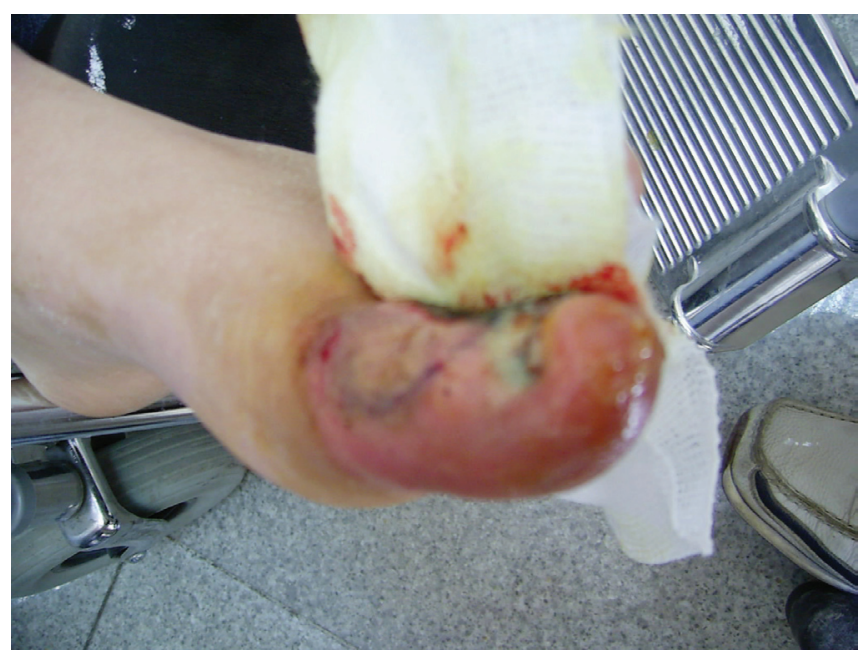

Şek. 2. Greft uygulaması sonrası postoperatif 7. gün

Hastanın takibinde greftlenen sahada herhangi bir problem yaşanmadi. Altıncı ayda fonksiyonel ve kozmetik olarak yeterli sonuç elde edildi (Şek. 3). Hastanın fizik muayenesinde sol ayak 1. parmaktaki hipoestezi bir miktar dönmekle birlikte hala vardı.

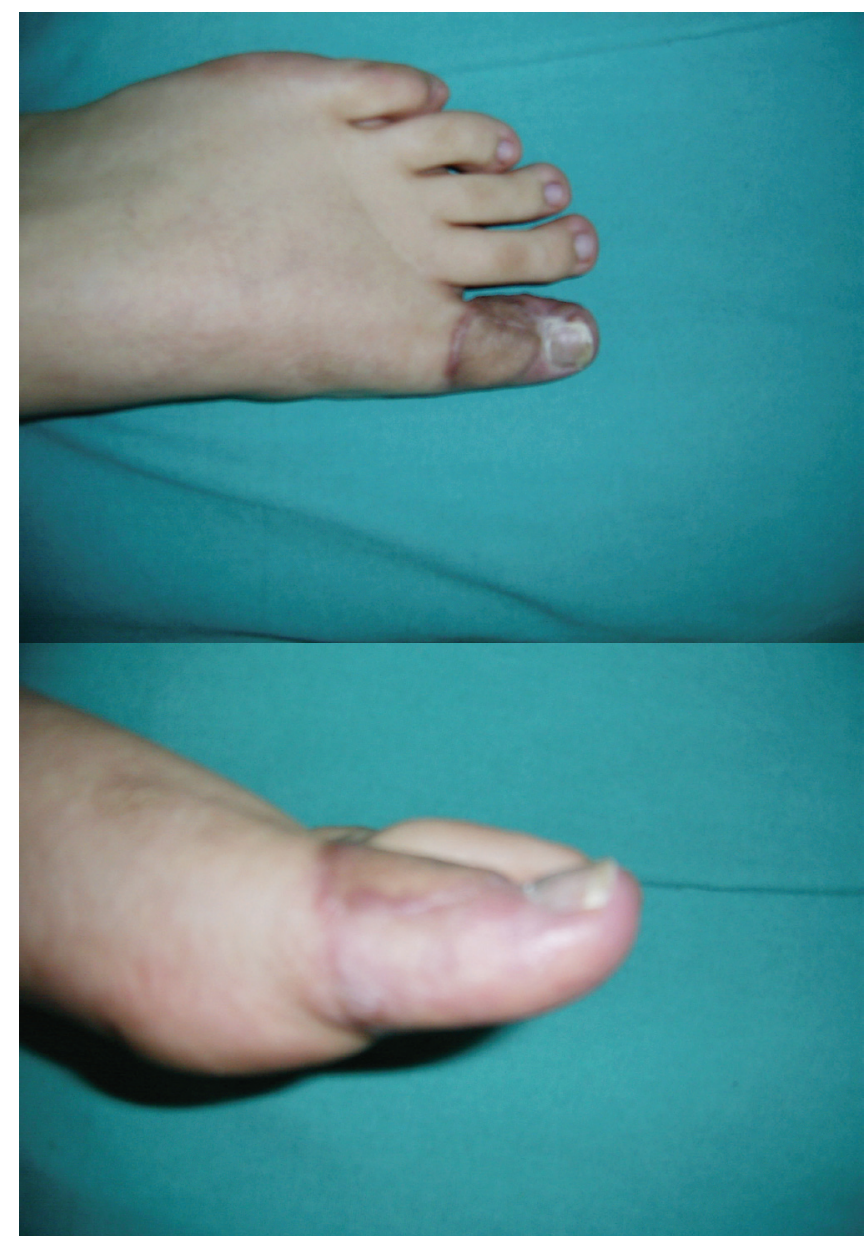

Şek. 3. Takiplerde 6. ay

\section{Tartışma}

Hastaya yapılacak cerrahi tek bir parmağa yönelik ise gereksiz doku iskemisini önlemek, dijital sinir bloğu yapabilmek ve hasta tarafindan uzun süre tolere edilebilmesi nedeni ile dijital turnikeler tercih edilir (Tucker ve Harris, 2002).

Pek çok çeşit dijital turnike tariflenmiş̧ir. Yaygın olarak penröz dren rulo haline getirildikten sonra parmağın en proksimaline çepeçevre sarılmakta ve klemplenmektedir (Aslan ve ark., 2003). Benzer bir şekilde penröz dren yerine Jacques üriner kateter kullanılabilir (Ray ve Flowers, 2001). Bu yöntemlerin dezavantajı parmağın distalinde venöz göllenme olması ve uygulanan basıncın yüksek oluşudur (Shaw ve ark., 1985; Ray ve Flowers, 2001; Aslan ve ark., 2003). Bir başka yöntem ise cerrahi eldivenin bir parmağının kesilip ucunun kaldırılması veya halka şeklinde kesilmesi ve parmağın distalinden proksimaline ilerleterek uygulanan yöntemdir (Salem, 1973; Tucker ve Harris, 2002). Bu yöntemin avantajı turnike uygulanan sahada venöz kanı proksimale ilerletmesi, dezavantaj 1 ise işlem sonunda unutulabilmesidir. Bu yöntemle uygulanan turnikede uzamış iskemi ve lokal anestezinin etkisi sebebi ile hasta turnikeyi hissetmeyebilir. Komplikasyonların çoğu iskemiye veya uygulanan basıncın fazla olmasına bağlıdır. Hixon ve ark. (1986)'nın yaptığı çalışmada cerrahi eldivenden halka şeklinde kesilen parmak turnikesinde parmağa uygulanan basınç $385 \mathrm{~mm} \mathrm{Hg}$ dir. Penröz dren uygulandığında basınç $675 \mathrm{~mm} \mathrm{Hg}$ ya ulaşabilmektedir. Ochea ve arkadaşlarının (1972) maymunlar üzerinde yaptı̆̆ çalışmada $500 \mathrm{~mm} \mathrm{Hg}$ basınç ile sinirlerdeki iletim hızının yavaşladığ gösterilmiştir. $500 \mathrm{~mm} \mathrm{Hg}$ altındaki basınçlarda Wallerian dejenerasyona ait bulgu gösterilmemiştir. Parmaklardaki kas 
miktarı azdır. Bu durum parmakları iskemiye duyarlı hale getirir. Sinirler ilk hasara uğrayan dokulardır. İskemi süresi uzadıkça diğer yumuşak dokular irreversible olarak iskemi, nekroz ve gangren sürecine girerler (Smith ve ark., 2002).

Turnikenin uygulanma süresi ve uygulanacak basınç tartışmalıdır. Çoğu yazar uygulama süresini alt ekstremitede 1,5-2 saat, basinc1 ise sistolik basıncın $100 \mathrm{~mm} \mathrm{Hg}$ fazlasını kabul eder. Dijital turnikelerin uygulama süresi ve uygulanan basınç kişiden kişiye, parmaktan parmağa ve uygulanan yönteme göre değişmektedir. Yarım cm çaplı penröz dren kullanıldığında drenin \%50 gerilmesi, 1 cm çaplı penröz dren kullanıldığında drenin \%33 gerilmesi yeterli basıncı sağlayacaktır. Hastanın eline uyan bir eldivenden kesilerek uygulanan halka şeklinde parmak turnikesi yeterli basınç sağlayacaktır (Shaw ve ark., 1985). Uygulama süresi tartışmalı olmakla birlikte 30 dakikadan kısa sürecek cerrahi işlemlerde nörovasküler yapılar üzerine zarar vermediği düşünülmektedir (Smith ve ark., 2002).

$\mathrm{Bu}$ olguda 48 saat turnike uygulaması ile gelişen nörovasküler hasar medikal tedavi, cerrahi debridman ve greftleme ile başarılı bir şekilde tedavi edilmiştir. Literatürde 1,5 gün ve 4 gün turnike uygulanan iki ayrı olgu medikal tedavi ve sülük uygulanarak tedavi edilmiştir (Avci ve ark., 2003; Durrant ve ark., 2006). Parmak turnikeleri uygulaması kolay, ucuz ve efektif yöntemlerdir. Komplikasyonlardan kaçınmak için turnike işlem sonunda unutulmamalı ve buna uygun yöntemler tercih edilmelidir.

\section{KAYNAKLAR}

Aslan, G., Sarifakioglu, N., Bingul, F., 2003. Simple and effective device for finger tourniquet: A rolled penrose drain. Plast. Reconstr. Surg. $111,1758-1759$.

Avci, G., Akan, M., Yildirim, S., Akoz, T., 2003. Digital neurovascular compression due to a forgotten tourniquet. Hand Surg. 8, 133-136.

Dove, A.F., Clifford, R.P., 1982. Ischaemia after use of finger tourniquet. Brit. Med. J. 284, 1162-1163.

Durrant, C., Townley, W.A., Ramkumar, S., Khoo, C.T., 2006. Forgotten digital tourniquet: Salvage of an ischaemic finger by application of medicinal leeches. Ann. Roy. Coll. Surg. 88, 462-464.

Hixon, P.F., Shafiroff, B.B., Werner, F.W., Palmer, A.K., 1986. Digital tourniquets: A pressure study with clinical relevance. J. Hand Surg. Am. 11, 865-867.

Ochoa J, Fowler TJ, Gilliatt RW., 1972. Anatomical changes in peripheral nerves compressed by a pneumatic tourniquet. J. Anat. 113, 433455.

Ray, P.S., Flowers, M.J., 2001. Digital tourniquet: A new technique. The Foot 11, 160-162

Salem, M.Z.A., 1973. Simple finger tourniquet. Brit. Med. J. 2, 79.

Shaw, J.A., Demuth, W.W., Gillespy, A.W., 1985. Guidelines for the use of digital tourniquets based on physiological pressure measurements. J. Bone Joint Surg. Am. 67, 1086-1090.

Smith, I.M., Austin, O.M., Knight, S.L., 2002. A simple and fail safe method for digital tourniquet. J.Hand Surg. Br. 27, $363-364$.

Tucker, S., Harris, P.C., 2002. The unforgettable finger tourniquet. Injury. 33, 76-77. 